\title{
A Novel Simplified Column-Switching Technique for the Determination of Traces of Bromate in High Concentration Matrices
}

\author{
Yali Shi, Yaqi Cai*, Jingsheng Liu, and Shifen Mou \\ The State Key Laboratory of Environmental Chemistry and Ecotoxicology, Research Center for Eco-Environmental Sciences, \\ Chinese Academy of Sciences, P.O. Box 2871, Beijing 100085, China
}

Received October 1, 2005; accepted February 23, 2006; published online May 11, 2006

(C) Springer-Verlag 2006

\begin{abstract}
The column-switching technique has been widely used to determine trace level ions in the presence of high concentration matrix. A novel simplified column-switching method is proposed where bromate (as a model compound) was determined using this technique. The switching time window was confirmed by the retention time of determined ions. This technique can completely carry out the same function as the other column-switching technique do, but only one extra ten-way injection valve coupled to ion chromatograph was used. By using column-switching technique, it is possible to determine $0.2 \mu \mathrm{g} \mathrm{L}^{-1}$ bromate in the presence of $100 \mathrm{mg} \mathrm{L}^{-1}$ chloride by direct injection of $2000 \mu \mathrm{L}$ without any pretreatment and the relative standard deviation (RSD) of the peak height for the eleven successive injections of $0.2 \mu \mathrm{g} \mathrm{L}^{-1}$ bromate solution is $23.1 \%$. The detection limit for bromate is $0.09 \mu \mathrm{g} \mathrm{L}^{-1}$, which showed the method was very sensitive. The technique has been applied to the determination of bromate in drinking water, and the spike recovery is in the range of $96-104 \%$.
\end{abstract}

Key words: Column-switching; bromate; high concentration matrix.

\footnotetext{
* Author for correspondence. E-mail: caiyaqi@ rcees.ac.cn
}

The determination of trace level ions is tough challenge for ion chromatography method especially in the presence of high concentration matrix, because the matrix usually mask peaks of interest or make the analytical column overload, which may makes the determination impossible and the lifetime to be shortened. To get a reliable analytical result, some suitable sample pretreatments are usually indispensable, whose major purposes include the matrix elimination and trace analyte enrichment. Up to now, many techniques have been developed to solve these problems, in which column-switching ion chromatography technique is the most widely used one.

At present, there are several kinds of columnswitching techniques used in ion chromatography. The first one is the column-switching technique in which two columns having different functional groups are used [1-4]. Because of the different selectivity to the analyte and matrix, the analyte enrichment and matrix elimination can be completed simultaneously. This technique was mostly employed to determine the trace level anions in weak acid. In addition, it is also reported that this technique could be employed to determine the metal ions. For example, Laikhtman et al. [2] used this technique to determine low $\mu \mathrm{gL}^{-1}$ level magnesium and calcium ions in brine (30\% sodium chloride matrix). The second one 
is the column-switching technique, usually named "heart-cut" column-switching technique, in which two columns containing the same functional groups are used [5-11]. And this technique has been employed as a general tool for the determination of trace anions in the presence of a high concentration matrix. But in this method, a six-step complicated procedure was needed to optimize the 'heart-cut' timing parameters [7].

Although the two above-mentioned column-switching techniques have many practical applications now, they still have some shortcomings remained to be overcome. For example, they all require at least two pumps and two six-way valves, which makes the instrument much more complicated. As a general accepted, too complicated instrument means more expensive and large uncertainty, which results in the very poor acceptability of these two methods. In addition, much greater system pressure change often involved in the two column-switching techniques when the instrument system switches between different positions. Is there any possibility to achieve a same or better analytical performance by using a more simple column-switching system? To get this goal, Huang et al. [12] proposed a simplified column-switching technique. In this technique a shorter concentrator column (such as Guard column) was employed instead of the second column in conventional column switching technique. In this way the system pressure was reduced and stabilized. In addition, by using this technique the column-switching time windows can be determined directly by standard solutions of the analyte. So the analysis time got shorter. Huang et al. [12-15] utilized this technique to determine trace level ions in several sample with much more complex matrix, such as the trace level bromate in drinking water, nitrate in high salt seawater and so on. And the result showed that the method detection limit could be reduced low- $\mu \mathrm{g} \mathrm{L}{ }^{-1}$ level by using this simplified column-switching technique. Though this technique avoided some drawback of conventional column-switching technique, it has some shortcomings. For example in the system four valves were necessary, which is still somewhat complicated for many laboratories.

In this paper, the simplified column-switching technique proposed by Huang et al. was further improved and simplified. This technique can completely carry out the same function of the matrix elimination and the trace analyte enrichment as the other columnswitching techniques do, but only one extra ten- way injection valve coupled to ion chromatograph was used. By using this system, the column-switching time window can be determined directly by standard solutions of the analyte. At the same time, the Dionex EG40 Eluent Generator System was used to generate high purity and contaminant free potassium hydroxide with different concentration on-line successively utilizing only deionized water as the carrier, which makes the background and background shift during the gradient much lower, and therefore is very helpful to get a low detection limit and a excellent reproducibility. We have used the described method to the determination of trace level bromate in tap water and bottled drinking water in China.

\section{Experimental}

\section{Instruments and Chromatographic Condition}

A Dionex model ICS 2000 ion chromatograph (Sunnyvale, CA, USA, http://www.dionex.com) equipped with a dual-piston (in series) pump, a Dionex IonPac AS19 analytical column $(4 \times 250 \mathrm{~mm})$ and an IonPac AG19 guard column $(4 \times 50 \mathrm{~mm})$ was used throughout. The detection was performed by Dionex DS6 conductivity detector. Suppression of the eluent was achieved by a Dionex anion ASRS electrolytic suppressor $(4 \mathrm{~mm})$ in the autosuppression external water mode. A $2000-\mu \mathrm{L}$ sample loop was used for injection. All tubing in the chromatography path (from the outlet of the pump to the exit of the suppressor) was PEEK (0.005 in. (0.125 mm) I.D.). Both instrument control and data collection was performed with a personal computer equipped with a Dionex Chromeleon 6.5 chromatography workstation. A high-pressure ten-way valve and a concentrator column (Dionex IonPac AG11-HC, $4 \mathrm{~mm}$ ) were employed for the column-switching concentration system. The installation is showed in Fig. 1.

\section{Reagents}

All reagents used were of analytical-reagent grade unless specified. All solutions were prepared with deionized water further purified by EASYpure LF system (Barnstead, USA, http:// www.barnsteadthermolyne.com) with a specific resistance of $18.3 \mathrm{M} \Omega \cdot \mathrm{cm}^{-1}$. Chloride standard solutions $\left(1000 \mathrm{mg} \mathrm{L}^{-1}\right)$ were purchased from National Research Center for CRM's (China, http://www.nrccrm.org.cn/). Bromate standard solution was obtained by dilution of a $1000 \mathrm{mg} \mathrm{L}^{-1}$ concentrated stock solution prepared by dissolving solid $\mathrm{KBrO}_{3}$ (ChemService, USA, http:// www.chemservice.com/) in deionized water. The stock solutions were stored in a refrigerator at $4{ }^{\circ} \mathrm{C}$. Standard solutions were prepared daily by serial dilution of the stock solution prior to use. The eluent was potassium hydroxide that was generated from Dionex EG40 on line, which runs in a linear gradient at a flow-rate of $1.0 \mathrm{~mL} \mathrm{~min}^{-1}$. All determinations were performed at $30^{\circ} \mathrm{C}$ and all samples were injected in triplicate. Four kinds of bottled drinking water are purchased from supermarket in China and one tap water is collected from the laboratory. 


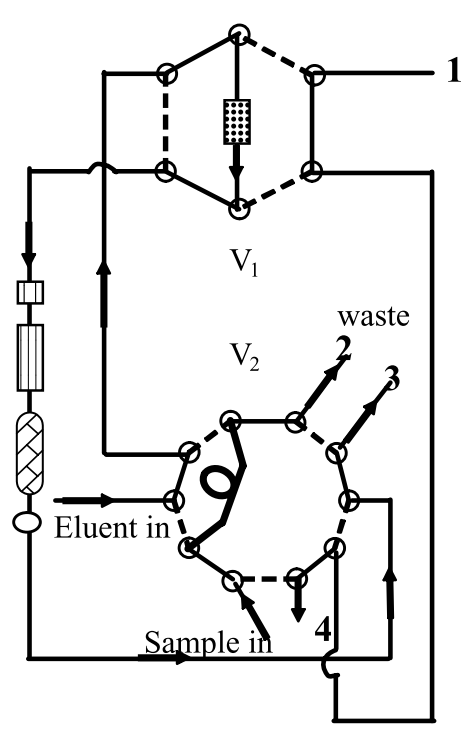

A

V1: load position

V2: load position

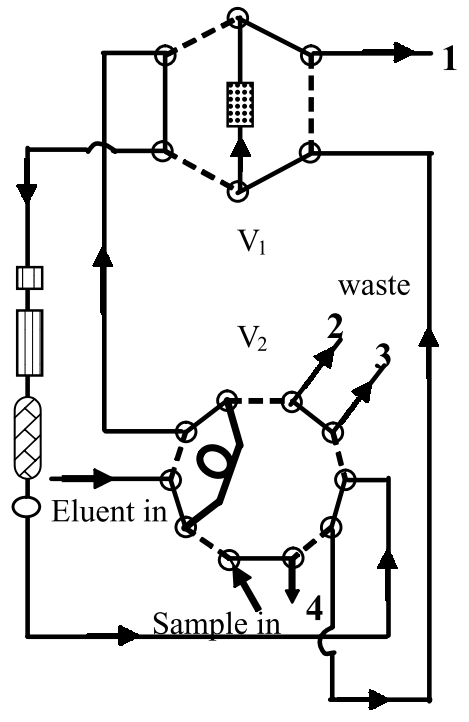

B

V1: injection position V2: injection position

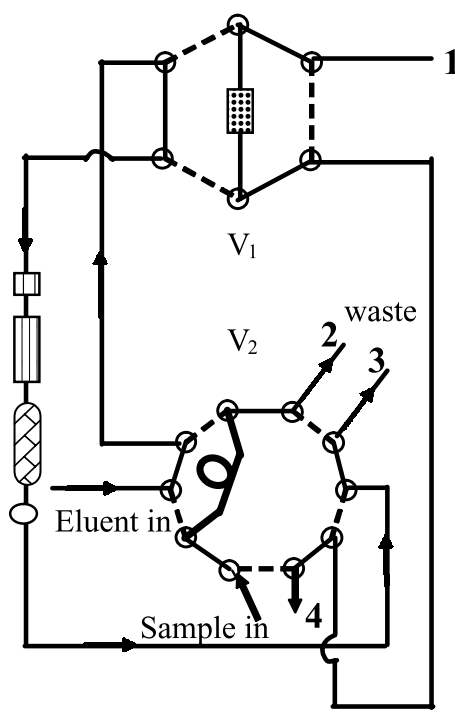

$\mathrm{C}$

V1: injection position

V2: load position

The ports 1, 2, 3, 4 are connected with the waste.

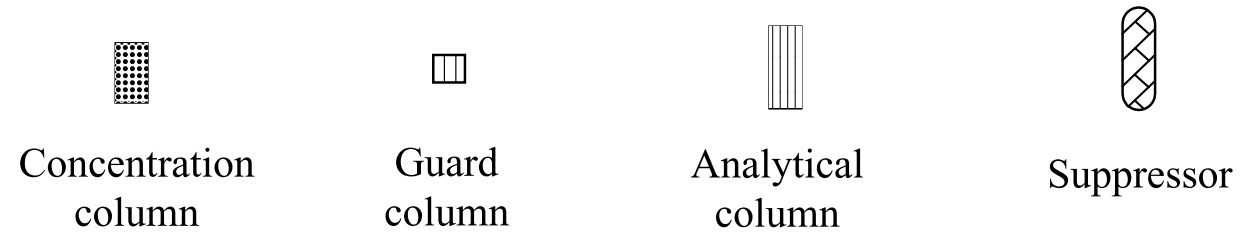

Fig. 1. Schematic diagram of the system; the flow path is shown as the bold line

\section{Results and Discussion}

\section{The Procedure of Method}

The procedure of method consists of the sample introduction, trace level ions enrichment, matrix elimination and trace level ions analysis. Firstly, introduction of the sample $(2 \mathrm{~mL})$ and running a "common separation" (shown in Fig. 1A); secondly, the trace level ions enrichment run, from $0 \mathrm{~min}$ to $10 \mathrm{~min}$ bromate was eluted from the analytical column and the effluent was collected onto a concentrator column in the direction opposite to the eluent flow (Fig. 1B). So the bromate can be concentrated in a compact band at the bottom of the concentrator column (AG11-HC). And then during the analytical run the bromate was "backflushed" with eluent from the concentrator column to analytical column and then determined. In that way bromate is rapidly eluted off the AG11-HC and onto the guard and analytical columns. If the sample is loaded onto the AG11-HC in the same flow direction as the eluent flow, bromate is concentrated at the head of the column rather than at the bottom. Such that the bromate will be slowly eluted off the AG11-HC, then the peak of bromate will get wider. So the enrichment was performed in a backflush manner. After eluent passed through an anion suppressor, it was changed into water, the weakest eluent for anion analysis. In this case, bromate was concentrated onto the AG11$\mathrm{HC}$ effectively. Thirdly, the matrix elimination procedure; when the matrix (chloride) was eluted from the analytical column, by switching the ten-way valve V2 (Fig. 1C) the majority of matrix and strongly retained anions in the samples were eluted from the column to waste. So the matrix elimination was achieved. And finally the concentrated ions are eluted and are separated on the same analytical column as was used for the original sample. That is to say the analytical run began V1 (Fig. 1A). 
Table 1. The program for the analyte enrichment, matrix elimination and analysis procedure

\begin{tabular}{|c|c|c|c|c|}
\hline Time (min) & $\begin{array}{l}\text { Hydroxide potassium } \\
\left(\mathrm{mmol} \mathrm{L}^{-1}\right)\end{array}$ & $\begin{array}{l}\text { The position } \\
\text { of six-way V1 }\end{array}$ & $\begin{array}{l}\text { The position } \\
\text { of ten-way V2 }\end{array}$ & Comments \\
\hline 0.0 & 10.00 & injection & injection & concentrated began \\
\hline $10.5^{\mathrm{a}}$ & 10.00 & injection & load & $\begin{array}{l}\text { concentrated end (matrix } \\
\text { elimination began) }\end{array}$ \\
\hline 15.0 & 10.00 & injection & load & matrix elimination \\
\hline 25.0 & 40.00 & injection & load & matrix elimination \\
\hline 25.1 & 10.00 & injection & load & matrix elimination \\
\hline 30.0 & 10.00 & injection & load & matrix elimination end \\
\hline 30.1 & 10.00 & load & load & analysis began \\
\hline 50.1 & 10.00 & load & load & analysis end \\
\hline
\end{tabular}

${ }^{a}$ This time can change with the analyte and matrix concentration.

The program utilized to complete the full cycle from introduction of the sample to the final determination of the target ion in this paper was shown in Table 1.

\section{The Selection of Chromatographic Parameter}

In this paper the determination of trace level bromate in drinking water as an example was studied. As indicated by Jeff et al. [16]. The use of highcapacity and hydroxide-selective anion-exchange column IonPac AS19 make the large volume injection possible, which can improve the sensitivity, so IonPac AS19 was adopted in our experiments. To get a low background conductance and good reproducibility, EG 40 was applied to generate the high purity potassium hydroxide eluent on-line. The better resolution of analyte and matrix ions is, the less the matrix ions which run onto the concentrator column is, and thus the less the interference of matrix is. It was found that the resolution of analyte and matrix ions gets better with the decrease of eluent concentration. But low eluent concentration results in too long retention time of strongly retained anions in the samples. So the eluent concentration must be carefully selected to achieve a good balance between the resolution and analysis time. In this paper, the eluent was run in a linear gradient. At the beginning the lower concentration eluent was used to improve the resolution of analyte and the matrix ions. And then the higher one was used to elute the strongly retained ions and shorten the analysis time. The linear gradient program for the analyte en-

Table 2. The program for rinsing system

\begin{tabular}{|c|c|c|c|}
\hline $\begin{array}{l}\text { Time } \\
(\mathrm{min})\end{array}$ & $\begin{array}{l}\text { Hydroxide } \\
\text { potassium } \\
\left(\mathrm{mmol} \mathrm{L}^{-1}\right)\end{array}$ & $\begin{array}{l}\text { The position } \\
\text { of six-way V1 }\end{array}$ & $\begin{array}{l}\text { The position } \\
\text { of ten-way V2 }\end{array}$ \\
\hline 0.0 & 10.00 & load & injection \\
\hline 15.0 & 10.00 & load & injection \\
\hline 25.0 & 40.00 & load & injection \\
\hline 25.1 & 10.00 & load & injection \\
\hline
\end{tabular}

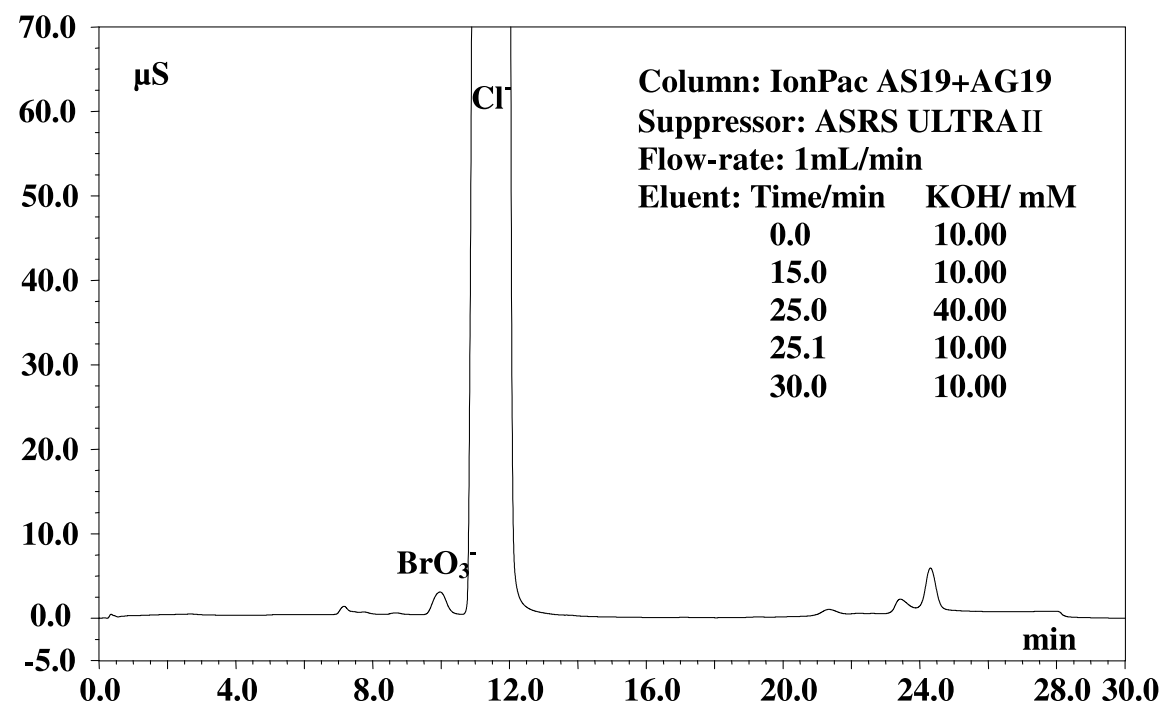

Fig. 2. The chromatogram of $600 \mu \mathrm{g} \mathrm{L}^{-1} \mathrm{BrO}_{3}^{-}$and $30 \mathrm{mg} \mathrm{L}^{-1} \mathrm{Cl}^{-}$ in standard solutions 
richment, matrix elimination and analysis procedure was showed in Table 1. The analysis procedure was from $30.1 \mathrm{~min}$ to $50.1 \mathrm{~min}$, during which the analyte was eluted from the concentrator column. In this paper the program for rinsing the system was set and showed in Table 2.

\section{The Determination of Switching Time Window}

The determination of switching time window is very important for the analyte enrichment and matrix elimination. In this paper the switching time windows can be determined directly by standard solu-
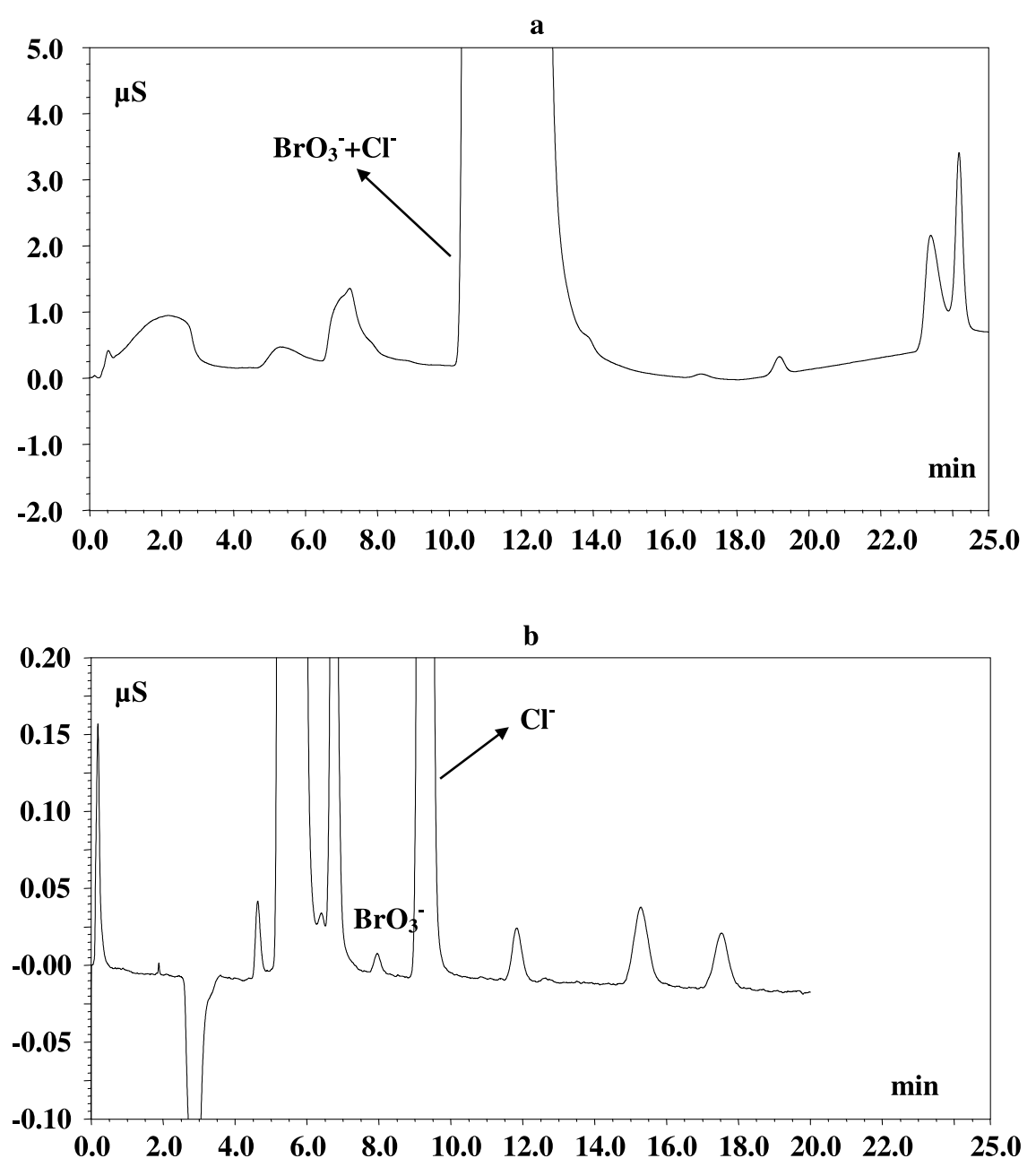

Fig. 3. The chromatogram of $1 \mu \mathrm{g} \mathrm{L}^{-1}$ $\mathrm{BrO}_{3}{ }^{-}$and $100 \mathrm{mg} \mathrm{L}^{-1} \mathrm{Cl}^{-}$in standard solution. (a) Before matrix elimination; (b) after the matrix elimination

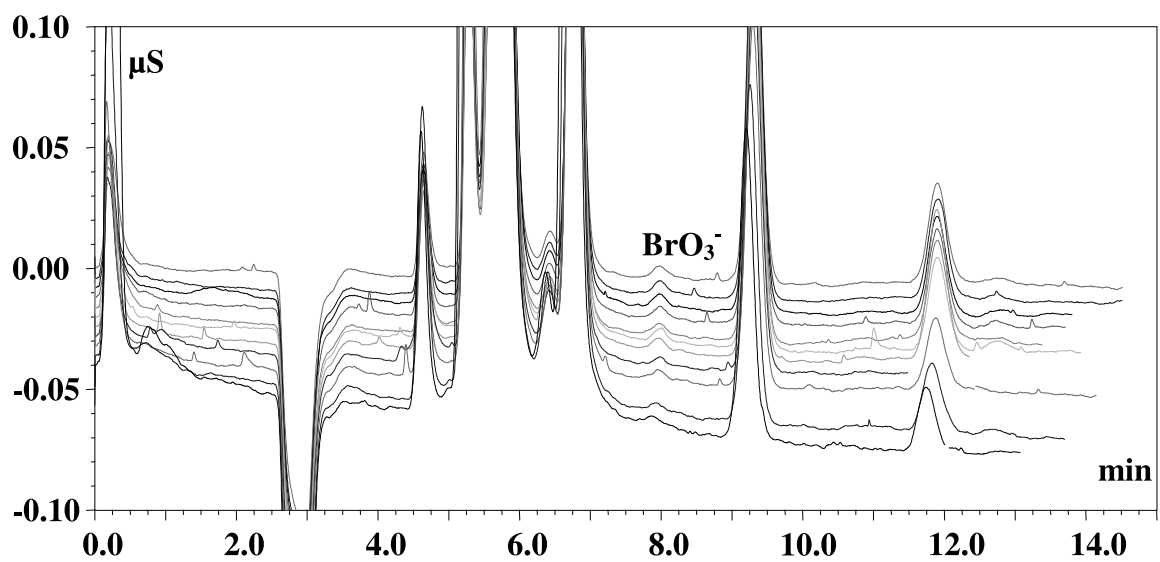

Fig. 4. Chromatogram of $0.2 \mu \mathrm{g} \mathrm{L}^{-1}$ bromate in the presence of $100 \mathrm{mg} \mathrm{L}^{-1}$ chloride eleven injections successively by column-switching 
tions of the analyte. When the standard solution was run, the time at which the analyte was eluted absolutely from analytical column to concentrator column was determined as the column-switching time windows. For example, the chromatogram of $600 \mathrm{\mu g} \mathrm{L}^{-1} \mathrm{BrO}_{3}{ }^{-}$ and $30 \mathrm{mg} \mathrm{L}^{-1} \mathrm{Cl}^{-}$in standard solution was showed in Fig. 2. As shown in Fig. 2 the retention time of bromate is $10.0 \mathrm{~min}$. To make the bromate eluted onto the concentrator column, 10.5 minute was determined as the switching time window. Because the retention time of bromate can change with the matrix concentration, the switching time window will change. It only took a short time, in which a sample was run once, to determine the switching time window.
The Selection of Concentrated Column

In this paper the concentration efficiency of four Anion Guard columns (AG19, AG14A, AG15, AG11-HC)

Table 3. The results of determination of bromate in drinking water and spiked standard

\begin{tabular}{lcccc}
\hline Samples & $\begin{array}{l}\text { Found } \\
\left(\mu \mathrm{g} \mathrm{L}^{-1}\right)\end{array}$ & $\begin{array}{l}\text { Spiked } \\
\left(\mu \mathrm{g} \mathrm{L}^{-1}\right)\end{array}$ & $\begin{array}{l}\text { Found } \\
\left(\mu \mathrm{g} \mathrm{L}^{-1}\right)\end{array}$ & $\begin{array}{l}\text { Recovery } \\
(\%)\end{array}$ \\
\hline DiYatian & 45.66 & 35.00 & 81.15 & 101 \\
Waha & 0.52 & 1.50 & 2.06 & 103 \\
Kangshi & 16.09 & 16.00 & 32.67 & 104 \\
Tap water & ND & 1.00 & 0.96 & 96 \\
Shanquan & 1.15 & 1.00 & 2.13 & 98
\end{tabular}
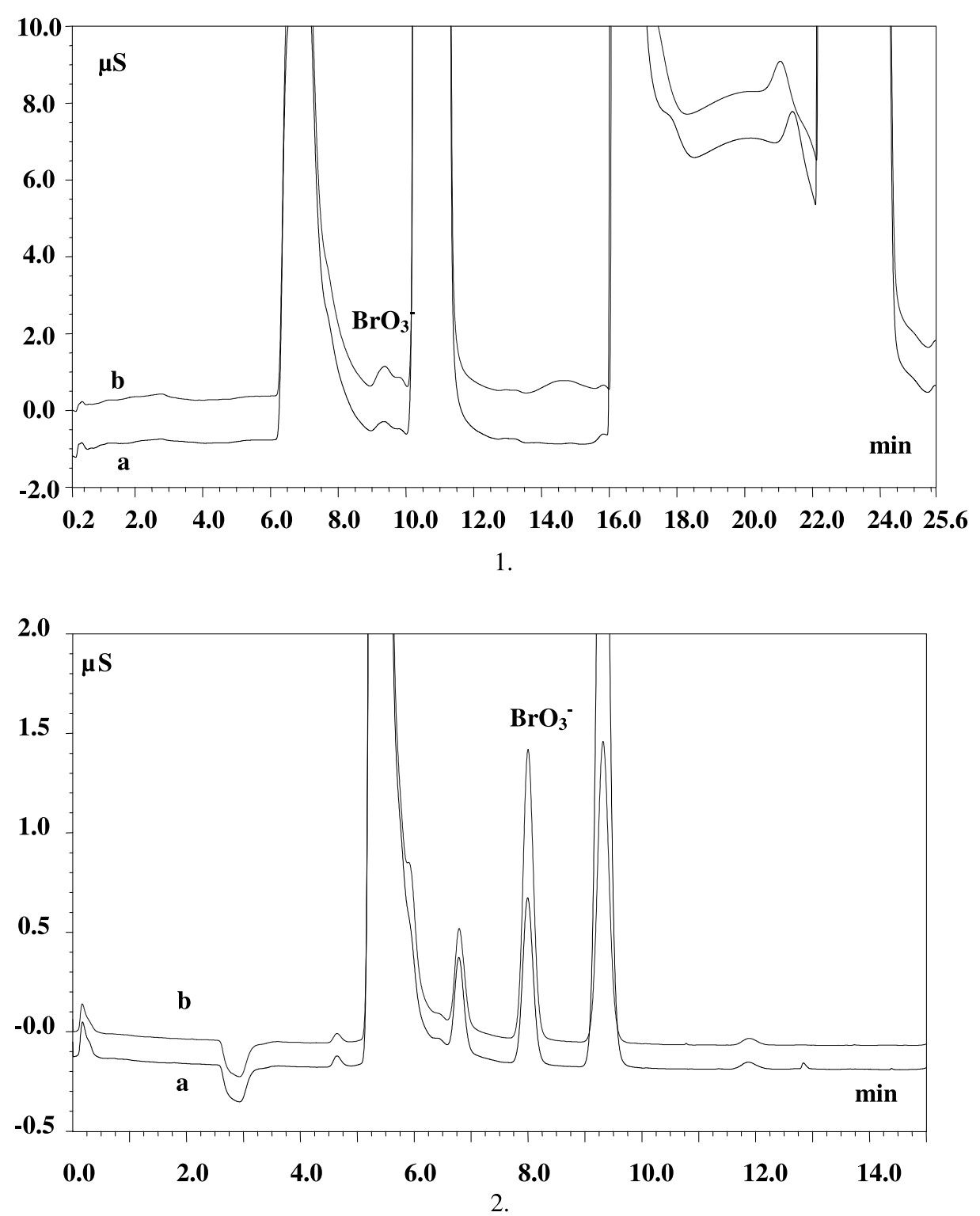

Fig. 5. The chromatogram of some brand bottled drinking water. (1) Before matrix elimination; (2) after the matrix elimination. (a) Original sample (with $45.66 \mu \mathrm{g} \mathrm{L}^{-1}$ bromate); (b) spiked sample (spiked with $35 \mu \mathrm{g} \mathrm{L}^{-1}$ bromate) 
as concentrator column on the bromate was studied. The result showed that AG11-HC was the best one for concentrating bromate. So AG11-HC was selected as concentrator column. The chromatograms of $1.0 \mu \mathrm{g} \mathrm{L}^{-1}$ bromate in the presence of $100 \mathrm{mg} \mathrm{L}^{-1}$ chloride were showed in Fig. 3. As showed in Fig. 3a, before the matrix was eliminated, the peak of $1.0 \mu \mathrm{g} \mathrm{L}^{-1}$ bromate was masked by the peak of $100 \mathrm{mg} \mathrm{L}^{-1}$ chloride absolutely. But after the matrix was eliminated, the bromate and the residual chloride can be separated very well (showed in Fig. 3b). So the bromate can be determined exactly.

\section{Precision and Detection Limit}

In order to validate the method for the analysis of bromate at $\mu \mathrm{g} \mathrm{L}^{-1}$ levels, the calibration graphs was generated using a $2000 \mu \mathrm{L}$ loop in the presence of $30 \mathrm{mg} \mathrm{L}^{-1}$ chloride. The peak height was used for calibration and quantitation. The detection limit and the linear ranges of the bromate are $0.09 \mu \mathrm{g} \mathrm{L}^{-1}(3 \mathrm{~S} / \mathrm{N})$ and $0.2-1000 \mu \mathrm{g} \mathrm{L}^{-1}$ respectively. The results showed that with a large-volume $(2000 \mu \mathrm{L})$ injection, the detection limit of bromate is at the $\mathrm{ng} \mathrm{L}^{-1}$ level and the linear correlation coefficient was 0.9998 . The linear range is over the typical concentration range for the bromate in real drinking water. By using column-switching technique, it should be possible to determine $0.2 \mu \mathrm{g} \mathrm{L}^{-1}$ bromate in the presence of $100 \mathrm{mg} \mathrm{L}^{-1}$ chloride by direct injection of $2000 \mu \mathrm{L}$ and the RSD of peak height for the eleven successive injections of $0.2 \mu \mathrm{g} \mathrm{L}^{-1}$ bromate solution is $23.1 \%$. The eleven injections overlay chromatogram was showed in Fig. 4.

\section{Analysis of Bromate in Drinking Water}

The described method has been applied to the determination of bromate in tap water and bottled drinking water in China. Recovery experiments were carried out by spiking with $1,1.5,16,35 \mu \mathrm{g} \mathrm{L}^{-1}$ in term of the concentration of bromate in bottled drinking water and tap water. The method showed a good recovery, ranging from $96 \%$ to $104 \%$ (Table 3). Chromatograms of DiYatian bottled drinking water sample, drinking water spiked with $35.00 \mu \mathrm{g} \mathrm{L}^{-1}$ bromate are reported in Fig. 5. As showed in Fig. 5, both the peak type of bromate and the resolution of bromate and chloride got better by using column-switching. The results showed that the method proposed in this paper could be used to eliminate the matrix efficiently.

\section{Conclusion}

This novel simplified column-switching technique performed accurate and precise analysis for the determination of trace level bromate in drinking water with high concentration of chloride at low cost without pretreatment. The result showed that the majority of matrix would be eliminated and the resolution of analyte and residual matrix would get better by using this technique. This technique will be better for the samples in which there is very high concentration of matrix. This column-switching technique is simpler than the other conventional one. This installation only consists of one six-way valve and one ten-way valve. It is possible to make the column switching achieved in one ion chromatography system in the future because this installation only has one extra ten-way valve compared with the conventional ion chromatography system.

Acknowledgements. This work was jointly supported by the National Natural Science Foundation of China (20577058, 20475060) and National Basic Research Program of China (2003CB415001).

\section{References}

[1] Kaiser E, Rohrer J S, Watanabe K (1999) J Chromatogr A 850: 167

[2] Laikhtman M, Riviello J, Rohrer J S (1998) J Chromatogr A 816: 282

[3] Stover F S (2002) J Chromatogr A 956: 121

[4] Rey M A, Riviello J M, Pohl C A (1997) J Chromatogr A 789: 149

[5] Colombini S, Polesello S, Valsecchi S (1998) J Chromatogr A 822: 162

[6] Bruno P, Caselli M, de Gennaro G et al (2003) J Chromatogr A 1003: 133

[7] Killgore J K, Villasenor S R (1996) J Chromatogr A 739: 43

[8] Galceran M T, Diez M (1994) J Chromatogr A 675: 141

[9] Kaiser E, Rohrer J (1999) J Chromatogr A 858: 55

[10] Peldszus S, Huck P M, Andrews S A (1998) J Chromatogr A 793: 198

[11] Dahllof J, Svensson O, Torstesson C (1997) J Chromatogr A 771: 163

[12] Huang Y, Mou S F, Liu K N, Riviello J M (2000) J Chromatogr A 884: 53

[13] Huang Y, Mou S F, Yan Y (1999) J Liq Chromatogr R T 22: 2235

[14] Huang Y, Mou S F (2000) Chin J Chromatogr 18: 95

[15] Huang Y, Mou S F, Rivielo J M (2000) J Chromatogr A 868: 209

[16] De Borba B M, Rohrer J S, Pohl C A, Saini C (2005) J Chromatogr A 1085: 25 